\title{
Qualified Money-A Better Financial System for the Future
}

\author{
Dirk Helbing
}

\begin{abstract}
Over millennia, people have seen the financial system collapse again and again. It is, therefore, time to re-invent money and the financial system altogether in order to make them fit for the complex world of today. Here, it is described how the idea for a new socio-ecological finance system came about. Three main innovations are proposed: (1) a particular combination of cash and electronic money, which promotes electronic transactions, while preserving privacy, where it is justified and needed; (2) money that has additional qualifiers such as reputation, which may depend on the geographic region, the exchange history, or other variables; (3) multidimensional money, which is better suited to manage complex systems such as our economy, and enables (the design of) self-organizing systems with favorable properties, e.g., economic systems that promote a co-evolutionary processes toward a circular economy.
\end{abstract}

\section{From Money to Bitcoin and Beyond}

To discuss the future of money, let us look back a little bit. By inventing a universally interchangeable good, the historical invention of money made the exchange of goods much easier. But while money was based on valuable materials such as gold in the beginning, it was later increasingly replaced by symbolic values, such as paper bills, or even entries in a digital account. Now, money is created in great amounts not only by central banks. Normal banks do it as well. If, one day, we don't trust anymore that we will get valuable goods in exchange, it is obvious that the value of money

\footnotetext{
This chapter describes how the Finance 4.0 idea (also abbreviated by FIN4, FIN4+, or FIN+) was born. A preprint of this slightly edited chapter is available here: https://futurict.blogspot.com/2014/ 10/qualified-money-better-financial-system.html and https://papers.ssrn.com/sol3/papers.cfm?abs tract_id=2526022.
}

D. Helbing ( $\varangle)$

ETH Zurich, Computational Social Science, Stampfenbachstrasse 48, 8092 Zurich, Switzerland e-mail: dhelbing@ethz.ch

M. M. Dapp et al. (eds.), Finance 4.0-Towards a Socio-Ecological Finance System, SpringerBriefs in Applied Sciences and Technology,

https://doi.org/10.1007/978-3-030-71400-0_2 
will be gone. This process is known as "hyper-inflation." In human history, this has happened many times.

Bitcoin is an attempt to avoid that such a horrible scenario can happen again. It's a peer-to-peer payment system, which does not require banks anymore. But it has other problems. Bitcoins are designed such that the overall amount of digital currency is slowly growing and saturating, thereby establishing something like a new "gold standard." However, in history, a classical gold standard alone has not been flexible enough for a resilient financial system. ${ }^{1}$ If the volume of money grows more quickly than economic output, there will eventually be inflation. Then, the value of money, i.e., its purchasing power, will drop. Conversely, if the volume of money does not grow as quickly as productivity, one may run into another problem, called "deflation." Then, money becomes more valuable over time, and people would hoard rather than spend it, as they can buy goods more cheaply in the future. Under such conditions, business cannot thrive. So, the volume of money should grow proportional to productivity, at least on average. Let me add though that the above dependencies regarding inflation and deflation are expected to hold only on the long run. Central banks and other stakeholders can manipulate financial markets, which may create delayed adjustments, biases, and abnormal market behaviors. As a consequence, it becomes increasingly difficult to interpret market signals correctly and to respond to them in a proper way. On the long run, I think, loss of control is almost inevitable.

\section{A New Kind of Money: How the Idea Was Born}

For the above reasons and due to the large amount of energy consumed, Bitcoin will not be the final solution, but the technological concept that is behind it will probably guide the way for future currencies and other services requiring secure transactions. Altogether, however, we need to fundamentally re-invent money, it is not adaptive enough for our complex world. We have to ask ourselves, why the financial system keeps crashing since thousands of years, and what is fundamentally wrong with the way we have set it up.

Thinking about this for a couple of years, I came to the conclusion that even though money is a great invention, it's outdated. Therefore, it's time to create a better one. The argument is as follows: Currently, money is a scalar, i.e., the simplest mathematical quantity one can think of. It is neither multi-dimensional nor does it have a memory. But mathematics offers a much richer spectrum of concepts to define exchange processes, such as multi-dimensional quantities, e.g., vectors,

\footnotetext{
${ }^{1}$ To make the gold standard more flexible, one could create gold-backed digital money with a time stamp. This would allow one to introduce "artificial aging" of money. In other words, such money would be most valuable when handed out, but it would lose its value exponentially over time. However, the same amount of money that would be lost in this way would be newly generated, for example, for the payment of basic income and investment premiums, see https://www. springerprofessional.de/democratic-capitalism/18842560 or http://futurict.blogspot.com/2020/07/ democratic-capitalism-why-not-give-it.html.
} 
tensors, matrices, or network graphs. In fact, money comes from somewhere and goes somewhere else. Who transfers money to whom defines a network of money flows. Therefore, money should be represented by network quantities. And money should be multi-dimensional to allow other things to happen apart from the eternal ups and downs.

This made me think about "Qualified Money"-multi-dimensional money with a memory. Since Roman times, people have said: "Money doesn't stink!" In other words, it does not matter where it comes from and how it is earned. However, what if we could give it a scent, like a perfume? And what if this would co-determine the value of money? In a discussion during a visit in Zurich, my colleagues Tobias Preis, David Rand, and Ole Peters were fascinated by this idea. Later on, I combined it with a reputation system and called the new concept "Qualified Money." Such money could earn reputation and, with this, additional value! This approach has commonalities with local currencies, but it is more general and relates to the way, modern stock markets work. However, Qualified Money opens entirely new possibilities.

\section{What's Wrong with Our Financial Architecture?}

One of the problems of today's financial system is the possibility of cascading effects. What started as a local problem in the Californian real estate market became a world financial and economic crisis, eventually causing social and political unrests. But how could it come that far? For this, see the Fig. 1 below. The world financial system lacks engineered breaking points to stop cascades. At home, every one of us has electrical fuses to make sure that a local electrical overload would not cause a larger problem, e.g., the house to burn down. In the financial system, however, the strategy is just the opposite: to ease the load on troubled banks, some of their problems have been taken on by the states, which are now in trouble as well, and so on. Rather than isolating infected "patients" and curing them by an intensive care program, one infected many other countries that were healthy before. In this way, the overall damage became much larger than it could have been, and it is not clear how we will ever recover from the resulting debt levels. If we don't get the problems solved any time soon, cultural values such as tolerance and solidarity, or even peace might be in danger. It's now the very fabric of our society, which is at stake. In societies with mass unemployment, it can take two generations or more until the good relationships between citizens and their state and a healthy social structure recovers.

What worries even more is the fact that we don't currently have a backup financial system. For most other systems that may fail, we have contingency plans-a "plan B" or "plan C." In fact, one might argue that one reason why our current financial system performs badly is the absence of competing financial systems. Given that we believe in competition, why don't we take this seriously and build alternative systems, which could also serve as backups, as plans B or C? It's not enough to complain about having to bail out banks and about lacking alternatives. I also doubt that tougher regulations won't fix the problems. As large banks can handle the additional 


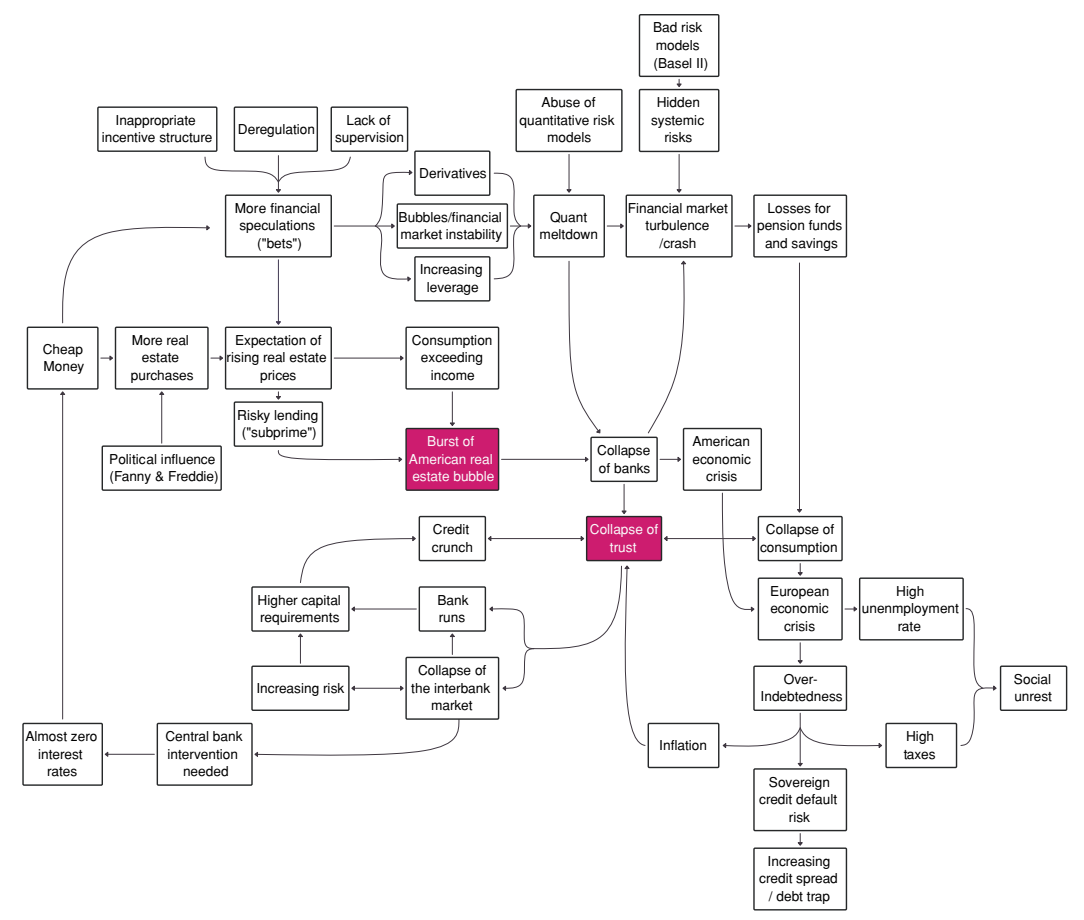

Fig. 1 How cascading effects in financial markets can come about

regulations best, while small- and medium-sized banks struggle with them, these regulations may cause big banks to grow even bigger. Therefore, we should rather promote alternatives. In fact, with Bitcoin and peer-to-peer lending systems, some alternatives are eventually emerging, but we need more and better ones.

At the moment, I would say that we cannot take it for granted that the current financial system will still work in 10 or 20 years from now. Most industrial states have debts of the order of $100 \%$ of the gross domestic product (GDP), sometimes even a multiple of this. Controlled inflation has been considered to be a recipe to reduce these debts. The trick can work, if applied by a single country or just a few ones. However, if the USA, Europe, China, Japan, and further countries are all trying to reduce their debts in such a way at the same time, this may trigger an inflationary spiral that can get out of hand.

Besides, the attempts of central banks to control the level of inflation haven't worked well so far. To save banks, to encourage investments into the real economy, and to increase the level of inflation, central banks have pumped massive, almost unimaginable amounts of money into the financial markets (under labels such as "quantitative easing"). However, as it turns out, years after the financial crisis started, many problems have still not been sorted out.

Why is this? Banks often do not trust that companies would pay their loans back and, besides, they need more capitalization themselves. Most money created 
by the central banks does not reach the companies in need. Instead, given the low interest rates, money is mainly invested in financial markets. This drives up stock prices even when real economic growth is negligible or negative. Rising stock prices create further incentives for virtual investments at the stock markets rather than real investments into companies. Consequently, central banks have created a gigantic bubble in the financial markets. In some sense, a virtual inflation has happened over there-the stocks have become more expensive even though most companies haven't grown. When this stock market bubble bursts, a large fraction of the money will flee into real values. This will suddenly drive enormous price inflation, as there are not enough material values that these huge amounts of money can buy. Therefore, inflation might easily get out of control. So far, this did not happen, as misleading incentives have caused a temporary allocation of money in the stock markets. In the meantime, however, low interest rates are undermining the perspectives of life insurances and pension funds.

\section{An Unfeasible Control Problem}

I have argued above that the central banks haven't been able to reach the effects they wanted. But this is not because they wouldn't be competent. It's because the control problem they are faced with is ill-defined-it's literally unsolvable. The reason is that they don't have enough instruments or, to put it differently, not enough control variables. The central banks can increase the volume of money, and they can change the interest rate. That's basically it. They may also buy and sell bonds, but many think they shouldn't. The classical instruments of central banks are apparently not sufficient to do the job. In other words, the weapons of central banks are blunt. New possibilities are urgently needed, and this basically means additional ways of adaptation.

Why is this so? Let's take an example from the world of taxes. Apart from raising money for public investments, taxes are often used to incentivize or discourage certain kinds of behaviors. For example, many countries have taxes on cigarettes, alcohol, and fuel, to reduce their consumption. They may also offer tax reductions for investments into environmental-friendly heating, better home insulation, or buying solar panels, to promote the production of renewable energy. It is clear that each of these goals can be achieved by suitable taxation-based incentives. But what happens if one simultaneously tries to reach many goals by one single "control variable," the overall amount of money to be paid for taxes? One may end up investing into solar energy production, while smoking more cigarettes, which altogether would not change the individual tax level. So, on average, people may not be very responsive to a multitude of rewards and sanctions. In other words, we are unlikely to reach many goals with a single control variable such as one-dimensional money. 


\section{More “Control Variables" Needed}

This problem is actually well-known from control theory. For example, complex chemical production processes cannot be steered by a single control variable such as the temperature or the concentration of a certain chemical ingredient. In a complicated production process, one must be able to control many different variables, such as the pressure and the concentrations of all ingredients. It is also instructive to compare this with ecosystems. The plant and animal life in a place will not just be determined by a single control variable such as the amount of water, but also by the temperature, humidity, and various kinds of nutrients such as oxygen, nitrogen, and phosphor. Our bodies, too, require many kinds of vitamins and nutrients to be healthy. So, why should our economic system be different? Why shouldn't a healthy financial system need several kinds of money?

If we had different kinds of money, we could probably influence how much of the money handed out by central banks is finally used by companies for real investments. This would require at least one additional kind of money. So, let us assume that, besides cash and goods, we would have two kinds of electronic money: "real" electronic money ("REMO") and "virtual" electronic money ("VEM"). For example, besides real electronic EUROs, we could introduce "AEROs" as virtual electronic money. By law, cash and real electronic money could be invested into goods and real investments, but not into financial products. Virtual electronic money, in contrast, could be invested into financial products, but not into goods. The important point is now that the central bank could hand out REMO and VEM at different interest rates. If REMO were handed out at a lower interest rate than VEM, this would incentivize real investments.

\section{Two Kinds of Electronic Money}

Of course, cash, REMO and VEM could be converted into each other. However, by means of conversion fees, one could also create incentives for one kind of money as compared to the other(s). This would create new "degrees of freedom", as a physicist would say, which would enable a better adaptation of the financial system to the actual needs. For example, if REMO earns some interest rate but cash not, or if cash loses value due to inflation, this speaks against saving large amounts of cash. It would be better to spend cash on consumption, or to turn it into REMO or VEM. If lending REMO is cheaper than lending VEM, it will incentivize real investments over virtual investments into financial products. If VEM can be converted into REMO for free, but converting REMO into VEM is costly, this again incentivizes real investments.

So, this little extension of our financial system will allow the central banks to more effectively stimulate real investments into companies' production capacities. Central banks would not have to produce anymore a bubble of cheap money, which will sooner or later overheat the financial and real estate markets. As we have seen in 
the past, this can cause dangerously large bubbles, which will sooner or later produce large-scale global damage, when they burst.

\section{Europe's “Little” Mistake}

But we should dare to think one step further. While the economy in the USA and the UK seems to be recovering from the 2008 financial crash and the subsequent economic crisis, most of Europe is still not doing well after several years of strugglein fact, some indicators are worse than after the great depression in the 1930s. In January 2014, Nobel Prize winner Joe Stiglitz (*1943) summarized the situation in Basel, Switzerland, as follows: before the crisis, Europe was doing very well. It had some of the strongest economies in the world, it had some of the best public infrastructures, best education systems, best health systems, and social systems. However, Europe did a "little" mistake: without creating a sufficiently sophisticated institutional framework, it introduced a new currency, the EURO, which replaced more than a dozen other currencies. Altogether, this created more problems than benefits, he judged.

We are not talking here about the widespread complaint of citizens that the introduction of the EURO made life more expensive-be it justified or not. Instead, we must talk about the fact that, if we compare all countries on a one-dimensional scale such as the gross domestic product (GDP) per capita, there will be always winners and losers. In this case, Germany happens to be a winner and Greece a loser, but it could have been different as well. We must recognize that, given the different productivity of the countries, it was just a matter of time until economic forces were unleashed, which required adjustments. In the past, such adjustments happened naturally by adapting the currency exchange rates. Now, in more than 15 European countries, this is not possible anymore. This problem can again be solved by adding new "degrees of freedom", or, as other people say, new "control variables". But how to introduce these variables without giving up the EURO, which many consider an important peace-building project in Europe?

\section{Vitamins for the Financial System}

In the following, I will suggest to introduce "Qualified Money." Qualified Money has a number of different qualifiers, which turn money into a multi-dimensional means of exchange. The value of Qualified Money is not only given by its amount, but also a conversion factor that depends on various qualities. For example, if one decided that geographic origin should be a qualifier, one would enable country-specific EUROs, allowing adjustments of the value of money to the respective economic strength. The same approach can be used to define regional or local currencies, if desired. So, one could save the prestige project of the "EURO" by making the currency more flexible. 
The regional variants of EUROs would be converted into each other similarly as we are currently doing it for different kinds of currencies at the stock markets, such as EUROs, DOLLARs, or YENs.

However, Qualified Money would not have to be connected to local origin. The concept has potential for extension. For example, the unemployment rate, the Millennium development goals, or any socio-economic-environmental factors considered relevant for human well-being could be used to define qualifiers. In our lives, it's not just money that matters. People care about many things, and this opens up entirely new possibilities!

\section{We Could All Be Doing Well}

It is important to recognize that both, the self-organization and management of complex dynamical systems, require sufficiently many control variables, not just one. Establishing different kinds of money would serve this purpose. Compared to the currency system we have today, these different kinds of money would not be easily convertible. There would be an adjustable conversion tax or fee, to discourage conversion and to encourage earning different kinds of money, instead. This would naturally extend the approach we have discussed before (in connection with VEM and REMO), and it would create a multi-dimensional incentive system, rewarding us for different kinds of efforts, including social and environmental ones.

Of course, such a conversion tax or fee would create something like "friction" in the multi-dimensional money system. However, we know from physics that friction can enable important functionality. How would it be to have such a multi-dimensional money and exchange system? Depending on how many dimensions we allow for, everyone could be doing well, each one on the dimensions fitting his or her personal strengths, skills, or expertise.

Today, we have many ranking systems to compensate for the lack of such a multi-dimensional money system. Besides the Fortune 500 list of richest persons, we rank tennis players and soccer players. Others collect medals or decorations, or even scores in computer games. Scientists enjoy citations earned by publications... Even though some of these ranking scales don't imply any material value, they can motivate people to make an effort. Hence, we can use such incentive mechanisms to create a multi-dimensional reward system, as we need it to enable self-organizing socio-economic systems.

One might even consider the possibility to allow everyone to establish a certain number of own currencies. In a sense, this would be the logical next step after allowing banks and Bitcoin (not just central banks) to create money. The value of these personalized currencies would then depend on how much others trust in them and are willing to engage in related value exchanges. I assume that, after some time, there would be just a reasonably small number of successful currencies that are widely used. However, they might have some interesting new properties compared 
to the currencies we have today. Therefore, opening up money creation to innovation might be really worthwhile.

\section{Money with a Memory}

Let us now assume that electronic money would be traceable. In this case, we could give electronic money a "memory," and we could make its value dependent on its transaction history. To put it in simple terms, money that went through the hands of Albert Einstein or John F. Kennedy could have more value than money that was earned with "blood diamonds." So, possible qualifiers could be, how the money was earned, its origin or destination location, the reputation of the products bought, or the reputation of the producer or seller. Hence, we can further differentiate electronic money by means of additional qualifiers. This might be imagined as treating money units like stocks or like individual currencies. In other words, a (reputation-dependent) conversion factor would apply, when financial transactions are made.

\section{Benefits of Money with Reputation}

I recognize that some people might feel uneasy about money becoming dependent on reputation. However, in some sense, this is already happening when we go shopping on the Internet. Depending on the country we live in, the type of computer we are using, and perhaps further personal qualifiers such as income, we might get different product offers than others, at different prices. This is part of the logic of personalized recommender systems. One might find it upsetting to pay a higher price than others, but it could also be a lower one. When we book an airplane ticket or a hotel room, we receive different offers, too, depending on when we book and where we book, and whether we are regular customers or not.

In any case, there are quite some benefits of reputation-based Qualified Money. For example, it becomes easier for producers and stores to sell high-quality products at a higher price. Furthermore, to get an idea how future shopping might look like, assume that there is a database, in which information about products is stored, such as the amount of money to be paid, ingredients, durability, level of environmentalfriendly production, level of socially friendly production, and much more. In addition, let's assume our smartphones know our preferences, for example, that we give the price a weight of 50\%, environmental-friendliness a weight of $30 \%$, and fair production a weight of $20 \%$, and that we want to avoid products with particular ingredients we are allergic against. Then, by scanning product codes and retrieving the related product information, our smartphone will recommend us the best fitting products. ${ }^{2}$

\footnotetext{
${ }^{2}$ Such a platform for more sustainable consumption has been presented in a recent publication: T. Asikis, J. Klinglmayr, D. Helbing and E. Pournaras, How value-sensitive design can empower
} 
Furthermore, if customers were willing to share their preference settings, producers and sellers could better tailor their assortment of products to the customer wishes. Therefore, customers would benefit as well. They would get more products they would really like to have.

\section{Balancing Transparency and Anonymity}

If properly set up, Qualified Money can create a good balance between transparency and anonymity, such that we can have the benefits of both. Transparency can promote more responsible and desirable behavior. It allows ethical values and higher quality to survive in a framework of free economic competition. In fact, a considerable fraction of people cares about ethics and fair products. Even financial investors are getting interested in ethical investments, as they tend to be more sustainable. At the moment, we often find ourselves in a situation, where the competition between companies is so harsh that they have to reduce production costs. This can sooner or later decrease salary levels, production standards, product quality, and/or sustainability. In the end, we may have lower salary levels or lower-quality products. Both will eventually impact producers as well. In contrast, reputation mechanisms could stop the undesirable downward spiral, by rewarding higher quality products and fairer production.

The question is, whether the transparency needed for such reputation systems will ever be reached? In fact, there is currently a trend toward more transparency of money flows. We have recently seen (some of) the Swiss banking secrecy melt away. Several times, whistleblowers have sold confidential information about private accounts to public authorities. "Off-Shore Leaks" has made international money flows more transparent as well. Furthermore, there seems to be a "follow the money" program that tracks individual money transactions. And presently, many countries set up agreements for an automatic information exchange allowing public authorities to monitor money flows and to check tax declarations.

Anonymous money exchange is under attack for similar reasons as anonymous information exchange: In many cases, it has promoted crime and misery. Nevertheless, anonymity has still important roles to play. Most of us don't want others to know, what medicine we buy in a pharmacy. For such and further reasons, we should still have some amount of cash besides traceable electronic money, even though it should lose its value quickly enough to make traceable transactions more attractive than cash.

It should be also remembered that anonymity is one of the most important elements of democracies. The principle of anonymous vote is needed for independent decision-making, which is a precondition for the "wisdom of crowds" to

sustainable consumption, Royal Society Open Science 8: 201418 (2021); see also the video accessible at https://www.youtube.com/watch?v=uur5BXXspgI. 
work. Academic peer review as well is based on anonymity, to support open criticism without fear of revenge. Organized crime or corruption would also be difficult to fight without protecting the anonymity of witnesses. So, neither full transparency nor full anonymity can work. We need a system that makes it possible to combine and balance both principles. Introducing Qualified Money besides cash is the solution!

How this would work is described in more detail in an invention, ${ }^{3}$ a FuturICT blog on Democratic Capitalism, ${ }^{4}$ as well as the main part of this book on "Finance 4.0" and its Appendix on the "Interaction Support Processor".

Open Access This chapter is licensed under the terms of the Creative Commons Attribution 4.0 International License (http://creativecommons.org/licenses/by/4.0/), which permits use, sharing, adaptation, distribution and reproduction in any medium or format, as long as you give appropriate credit to the original author(s) and the source, provide a link to the Creative Commons license and indicate if changes were made.

The images or other third party material in this chapter are included in the chapter's Creative Commons license, unless indicated otherwise in a credit line to the material. If material is not included in the chapter's Creative Commons license and your intended use is not permitted by statutory regulation or exceeds the permitted use, you will need to obtain permission directly from the copyright holder.

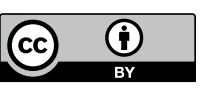

\footnotetext{
${ }^{3}$ D. Helbing, Interaction Support Processor, see https://patents.google.com/patent/US2016035068 $5 \mathrm{~A} 1 / \mathrm{en}$.

${ }^{4}$ See http://futurict.blogspot.com/2020/07/democratic-capitalism-why-not-give-it.html, to be published in D. Helbing, Next Civilization (Springer, 2021).
} 